\title{
LETTER
}

\section{Rapidly scalable mechanical ventilator for the COVID-19 pandemic}

\author{
Albert H. Kwon ${ }^{1}$, Alexander H. Slocum Jr ${ }^{2}$, Dirk Varelmann ${ }^{3}$, Christoph G. S. Nabzdyk ${ }^{4^{*}}$ (D) on behalf of the \\ MIT E-Vent Team
}

() 2020 The Author(s)

The SARS-CoV-2 pandemic is straining healthcare systems worldwide, and a global ventilator shortage is fueling the dire situation. As a response, the MIT E-Vent Team (S1) manufactured a scalable ventilator prototype for mass production and demonstrated basic clinical feasibility.

MIT E-Vent engineering information and capabilities, but also missing safety features are provided on the MIT E-Vent website (https://e-vent.mit.edu/) and in the attachments (Fig. 1a, S2). Pressure-based alarms were implemented including in the 'Spiro Wave' device that is based on the MIT E-vent and was just authorized for emergency use by the US FDA. In brief, the MIT E-Vent houses a manual resuscitator, an external compression mechanism, and a control system for adjusting tidal volumes, inspiration-to-expiration ratio, and respiratory rate (Fig. 1a, S3, S4). The MIT E-Vent is equipped with a pressure relief and a positive end-expiratory pressure (PEEP) valve. It delivers unassisted (Fig. 1b) and assisted (not shown) volume control ventilation (VCV). As a proof of concept, a pig was ventilated with the MIT E-Vent or a standard mechanical ventilator (SMV) at distinct settings and arterial blood gases, ventilator waveforms, and flowvolume loops were obtained.

The MIT E-Vent performed similar to a SMV at identical respiratory settings. After $36 \mathrm{~h}$ of usage including at high demand settings (TV 600 cc, RR 30, PEEP 20), no signs of device failure were noted (S5).

*Correspondence: nabzdyk.christoph@mayoedu

${ }^{4}$ Department of Anesthesiology and Perioperative Medicine, Mayo Clinic, Rochester, MN, USA

Full author information is available at the end of the article

Albert H. Kwon and Alexander H. Slocum Jr they have contributed equally to this work.

The MIT E-Vent Team group details are listed in the acknowledgement section.

\section{Tidal volume delivery}

MIT E-Vent waveforms showed a smooth tidal volume delivery (Fig. 1b). It revealed similar flow-volume loops when compared to manual ventilation using a manual resuscitator (Fig. 1c).

\section{Gas exchange}

MIT E-Vent settings were changed to achieve 'low' and 'high' minute ventilation, and 'low' and 'high' FiO2 states as reflected in the ABGs (Fig. 1d, e).

The MIT E-Vent provides (un-)assisted VCV, variable $\mathrm{MV}$, and PEEP with airway pressure profiles comparable to a SMV. The MIT E-Vent is not equipped to provide pressure control ventilation (PCV), which may make it unsuitable for awake and the most complex ARDS patients. However, this device is meant as a bridging tool when a conventional ventilator is not available, to serve as 'destination ventilator device' in the absence of any alternatives, or to help free up SMV in certain cases.

The MIT E-Vent Team was determined to equip the MIT E-Vent with comprehensive safety features including oxygen and flow sensors, but due to widespread hardware supply shortages, this became impossible. Omitting these safety features was deemed necessary to provide a rapidly scalable prototype. Consequently, increased clinical monitoring is required to provide adequate safety during the use of the MIT E-Vent (S2). Despite these limitations, the MIT-E Vent offers basic mechanical ventilation for selected patients during this ventilator shortage.

\section{勿




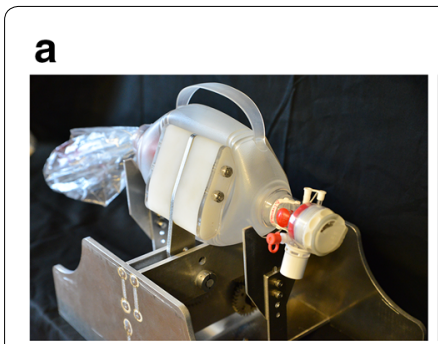

b

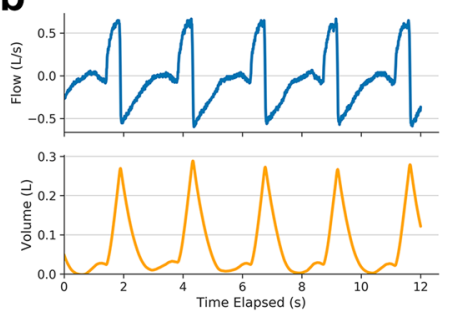

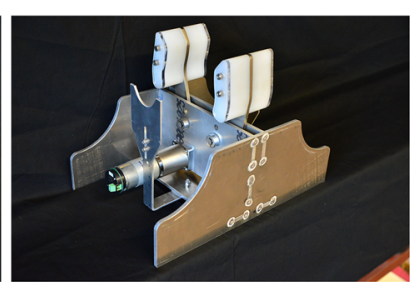

C

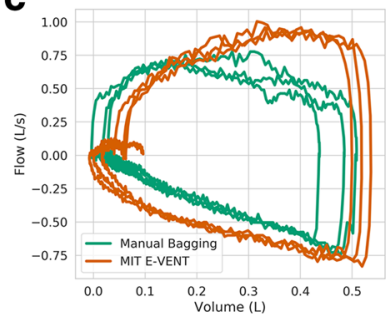

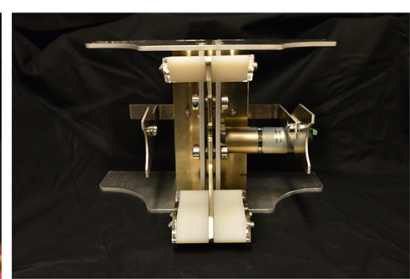

d Arterial pCO2 Levels in Response to MIT E-Vent
Minute Ventilation Adjustments in a Pig

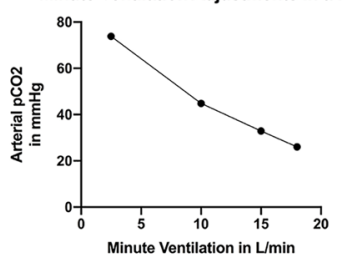

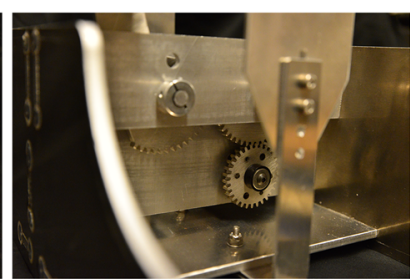

e

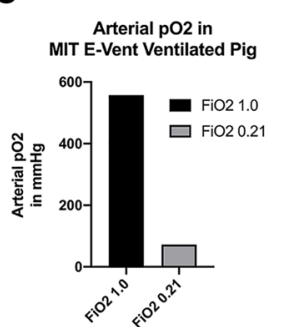

Fig. 1 MIT E-Vent. Prototype design (a). Waveforms and flow-volume loops (b and $\mathbf{c})$. Ventilation (d) and oxygenation testing (e)

The MIT E-Vent Team invites the global community to improve and distribute a version of this scalable, low-cost ventilator during this COVID-19 pandemic.

Oxygenation and ventilation capabilities of a scalable, low-cost ventilator were demonstrated. MIT E-Vent engineering documentation was made public to rapidly implement the MIT E-Vent into the clinical care of patients requiring invasive mechanical ventilation.

\section{Electronic supplementary material}

The online version of this article (https://doi.org/10.1007/s00134-020-06113-3) contains supplementary material, which is available to authorized users.

\section{MIT E-Vent Team}

MIT E-Vent Engineering: Brandon Araki - PhD Candidate, Computer Science and Artificial Intelligence Laboratory (CSAIL), MIT Murad Abu-Kalaf, PhD Research Scientist, Computer Science and Artificial Intelligence Laboratory (CSAIL), MIT Mike Detienne, BS - MIT Alum (Electrical Engineering) David Hagan, PhD - CEO, QuantAQ; MIT Alum, (Atmospheric Physics \& Chemistry) Nevan Hanumara, PhD - Research Scientist, Mechanical Engineering, MIT (Alum) Kimberly Jung, MS, MBA - MIT Alum (Mechanical Engineering) Teddy Ort - PhD Candidate, Computer Science and Artificial Intelligence Laboratory (CSAIL), MIT Aaron Ramirez - PhD Candidate, Mechanical Engineering, MIT Folkers Rojas, PhD - Founder, Raptor Designs; MIT Alum (Mechanical Engineering) Daniela Rus, PhD - Director, Computer Science and Artificial Intelligence Laboratory (CSAIL), MIT Amelia Servi, PhD - R\&D Engineer, Creare, LLC; MIT Alum (Mechanical Engineering) Shakti Shaligram, MS - Research Scientist, IDM; MIT Alum (Integrated Design and Management) Alexander Slocum, PhD - Professor of Mechanical Engineering, MIT Jonathan Slocum, ScD - MIT Alum (Mechanical Engineering) Alexander Slocum, Jr, MD PhD - Department of Plastic \& Reconstructive Surgery, Medical College of Wisconsin; MIT Alum (Mechanical Engineering) Coby Unger, BS; MIT Hobby Shop. MIT E-Vent Clinical Team: Jay Connor, MD - Orthopaedic Surgery, Mt Auburn Hospital Bon Ku, MD - Assistant Dean for Medical Education and Associate Professor of Emergency Medicine, Thomas Jefferson University, Sidney Kimmel Medical College Albert Kwon, MD - Assistant Professor of Anesthesiology, Department of Anesthesiology, Westchester Medical Center, New York Medical College Christoph Nabzdyk, MD - Assistant Professor of Anesthesiology, Department of Anesthesiology and Perioperative Medicine, Mayo Clinic, Rochester Alexander Slocum, Jr, MD PhD - Department of Plastic \& Reconstructive
Surgery, Medical College of Wisconsin Dirk Varelmann, MD - Assistant Professor of Anesthesiology, Department of Anesthesiology, Perioperative and Pain Medicine, Brigham and Women's Hospital, Harvard Medical School. Clinical Advisors: John Callahan, MD - Internal Medicine, St. Joseph's Hospital Health Center \& Veterans Administration Hospital, Syracuse Sergey Karamnov, MD Instructor of Anesthesiology, Perioperative and Pain Medicine, Brigham and Women's Hospital, Harvard Medical School Keith G Lurie, MD - Professor of Emergency Medicine, University of Minnesota Niels Olson, Lt Cmdr, MD Laboratory Medical Director, US Naval Hospital, Guam; Professor, Uniformed Services University Neil Ray, MD - Anesthesiologist; Founder \& CEO, Raydiant Oximetry Mark Rosen, MD - Professor of Anesthesiology (Ret), University of California, San Francisco; CMO, Raydiant Oximetry Steven Shafer, MD - Professor of Anesthesiology, Perioperative and Pain Medicine, Stanford University Scott Sparks, Lt Col, MD - Anesthesiologist, US Naval Hospital, Guam. Manuscript Composition and Editing Leena: Pradhan-Nabzdyk, PhD, MBA - Assistant Professor of Surgery, Division of Vascular and Endovascular Surgery, Beth Israel Deaconess Medical Center, Harvard Medical School. 2010 2.75 Project Team: Amelia Servi, PhD - R\&D Engineering, Creare, LLC Abdul Mohsen Al Husseini, PhD - Co-Founder \& Chief Strategy Officer, Analytical Space, Inc. Justin Negrete, MS - Thermal Engineer, Ford Motor Company, Inc. Stephen Powelson, BS - Senior Mechanical Engineer, Rani Therapeutics, LLC Heon Ju Lee, PhD - Executive Director, Kyperion Co. Ltd.

\section{Author details}

${ }^{1}$ Department of Anesthesiology, Westchester Medical Center, New York Medical College, Valhalla, NY, USA. ${ }^{2}$ Department of Plastic and Reconstructive Surgery, Medical College of Wisconsin, Wauwatosa, WI, USA. ${ }^{3}$ Department of Anesthesiology, Perioperative and Pain Medicine, Brigham and Women's Hospital, Boston, MA, USA. ${ }^{4}$ Department of Anesthesiology and Perioperative Medicine, Mayo Clinic, Rochester, MN, USA.

\section{Compliance with ethical standards}

\section{Conflicts of interest}

On behalf of all authors, the corresponding author states that there is no conflict of interest.

\section{Open Access}

This article is licensed under a Creative Commons Attribution-NonCommercial 4.0 International License, which permits any non-commercial use, sharing, adaptation, distribution and reproduction in any medium or format, as long as you give appropriate credit to the original author(s) and the source, provide a 
link to the Creative Commons licence, and indicate if changes were made. The images or other third party material in this article are included in the article's Creative Commons licence, unless indicated otherwise in a credit line to the material. If material is not included in the article's Creative Commons licence and your intended use is not permitted by statutory regulation or exceeds the permitted use, you will need to obtain permission directly from the copyright holder. To view a copy of this licence, visit http://creativecommons.org/licen ses/by-nc/4.0/.
Publisher's Note

Springer Nature remains neutral with regard to jurisdictional claims in published maps and institutional affiliations.

Accepted: 11 May 2020

Published online: 25 June 2020 